\title{
Debates About EdTech in a Time of Pandemics Should Include Youth's Voices
}

\author{
Velislava Hillman ${ }^{1}$ (D) João Pedro Martins² ${ }^{2}$. Emmanuel C. Ogu ${ }^{3}$ (D
}

Accepted: 12 April 2021 / Published online: 23 April 2021

(c) The Author(s), under exclusive licence to Springer Nature Switzerland AG 2021

\begin{abstract}
The EdTech debate continues to gather attention among academia, digital rights and privacy advocates, and the general public. While much ink is spilled by EdTech critics, with best interest for students facing a datafied and platformised education at heart, youth's voice is rarely present. Much is written about what EdTech means for education processes and what they might do to students or for them than is said in their own words. With the pandemic having kept children and youth at a computer distance from each other and society for over a year, what has been happening in their lives during this time should be heard - in their own words. This article follows on two emergencies gripping education globally as highlighted during the 2020 United Nations Internet Governance Forum (IGF), emphasised by two IGF youth representatives. On one hand, the pandemic crisis has exacerbated digital inequalities worldwide; on the other, the 'overdigitisation' of education has increased the risks of dataveillance and privacy loss. These two extremes intersect in their technodeterministic drive, which risks side-lining students' perspectives. To counter this risk, this paper brings these youths' perspectives and reflections over the dichotomy of 'none' versus 'too much' EdTech and what 'works' and does not in their learning in a time of pandemic.
\end{abstract}

Keywords Postdigital · EdTech · Digital divide · Youth · Digital surveillance · Covid-19

Velislava Hillman

v.hillman@1se.ac.uk

João Pedro Martins

jpdmartins@dei.uc.pt

Emmanuel C. Ogu

ecoxd1@yahoo.com

1 London School of Economics and Political Science, London WC2A 2AE, UK

2 Centre for Informatics and Systems, University of Coimbra, Pólo Il-Pinhal de Marrocos, 3030-290 Coimbra, Portugal

3 Department of Information Technology, School of Computing \& Engineering Sciences, Babcock University, Ilishan-Remo, Ogun State, Nigeria 


\section{Introduction}

Digitising education has garnered concerns - from academia (Andrejevic and Selwyn 2019), to human rights and privacy advocates (Persson 2020), to the general public (Strauss 2020; Fleming 2021). While much ink is spilled by education technology critics (Williamson 2017; Selwyn 2014) and academics generally (Yu and Couldry 2020) with best interest for students facing a datafied (Van Dijck 2014) and platformised (Hillman et al. 2020) education at heart, youth's direct voice is rarely present. In a time when advancing digital technologies are pushing the collective imagination of what 'postdigital' world should mean beyond its perception of a 'messy and paradoxical condition' (Andersen et al. 2014; 5 in Jandrić et al. 2018: 893), youths' voices and perspectives should be heard and acknowledged when it comes to the messy and paradoxical condition of a postdigital education ecosystem.

Much is written about education technologies' (EdTech) implications to education and to students than is said in their own words. While bringing critical debates about the growing issues of dataveillance, human rights, and freedoms surrounding education and EdTech is vital, those for whom education is to begin with should be given the opportunity to speak and share their experiences. Thus, for instance, debates surrounding climate change have recently made youth voice stand out prominently (Maris 2019).

As the pandemic continues to keep children and young people at a computer distance from each other and society, but even after physical distancing no longer applies, what happens in their lives should be heard - in their own words. Their current lives have been strained by the pandemic in unprecedented ways. Education for many has remained online (Henley 2021; Coughlan 2021). Unemployment among young adults has spiked since the first pandemic lockdown (European Parliament 2020; Parker, Horowitz, and Brown 2020). Major examinations have been postponed (Blackall 2021). Some youths have suffered emotionally (Mondragon et al. 2021). Even interim jobs have become impossible to experience, next to internships and campus life (Reidy 2020; Grubic, Badovinac, and Johri 2020).

This paper has two objectives. First, it aims to bring the voice of youth in the place it deserves - among other academic work concerned about and exploring the promises and perils of EdTech in a time of pandemic and in general. And second, it aims to emphasise the need that youth's direct voice should make way not only in academic literature but also in the decision-making of the private sector and policy makers with regards to what works and gets to mediate education processes.

These objectives are expressed in a conversation among the three authors following their presentation during the United Nations' Internet Governance Forum in November 2020.

In the authors' collective view, two emergencies are gripping education globally. On the one hand, the pandemic crisis has exacerbated digital inequalities (Stiglitz 2020); on the other, the 'overdigitization' of educational processes 
has increased the risks of dataveillance and privacy loss ( $\mathrm{Li}$ and Lalani 2020). These two extremes intersect in their techno-deterministic drive since, in the first instance, the need is for more access to technologies, and in the second, technologies mediate most of the learning, which risks side-lining students' voice of experience and perspective. To counter this risk, this paper brings the perspective of what youth experience and think about the dichotomy of 'none' versus 'too much' EdTech.

\section{About the Conversation}

In November 2020, the United Nations Internet Governance Forum hosted its Youth Internet Governance Forum ${ }^{1}$ (IGF) alongside workshops, and presentations of representatives from policy, industry, and civil society from all corners of the world. Velislava, along with an informal working group of researchers and academics, presented on the topic of Children's and Youth's Rights and Participation in Internet Governance where she invited Emmanuel and João as Youth Ambassadors to the IGF to actively join as speakers in the session. Following this presentation, the conversation among Velislava, João, and Emmanuel further expanded to discuss how young people faced the pandemic lockdown and the perceived extreme conditions in which their schooling and life had to go on. These conversations were conducted via a series of emails which were eventually put in a final writing.

\section{Before and After Pandemic Inequalities}

Velislava Hillman (VH): What do you think is different about the inequalities in education now as a result of the pandemic crisis? Lack of resources (UNESCO 2020) and even access to basic necessities to obtain education (Amato 2015; Sellgren 2019) existed before the pandemic; could you give examples of the kinds of inequalities you experienced and what new emerged following the pandemic?

João Pedro Martins (JPM): During the first few months of the pandemic crisis, education was forced to go digital. Students were home, teachers were also home, and school got to be reinvented from day to night. When the educational process is centralised in a physical space where everyone can gather and benefit from the same infrastructural resources, all a teacher has to do is come in and teach, and all students need to do is come in and learn. With Covid-19, studying and teaching from home, that is completely not true and that would be my first inequality remark: not every student (and some teachers as well) has a personal computer or a stable and proper Internet connection that allows for synchronous communication at home (Kewalramani , Arnott, and Dadranou 2020). And when these resources were present at home, many had to share them not only with their siblings that were also home-schooled but also with their parents who were working remotely from home.

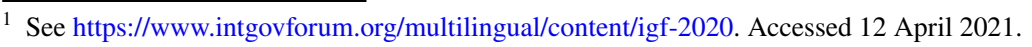


Now, let us add another layer of complexity and assume all had a digital device and Internet connection. Do all students have the technical skills required to allow for focusing on the education process rather than in the platforms and applications operations? Do all parents know how to help their children when such doubts arise? Again, a big no - another inequality I can identify (Zhang and Livingstone 2019). Most inequalities that were amplified arised from moving from a centralised to a decentralised paradigm without the proper time to reason with how to connect the dots.

Emmanuel C. Ogu (ECO): The rapid transitions from usual in-person to remote learning and teaching meant that rural dwellers, as well as others on the fringes of the digital divide (particularly in the base of the pyramid of developing and underdeveloped countries) such as those who are not tech-savvy, unable to afford digital tools and resources, were effectively marginalised by these transitions (Ceres 2020). If you have ever tried to complete a Massive Open Online Course (MOOC), then you probably already understand the depth of maturity, focus, patience, and consistency that often is required in order to complete any course successfully, even with dedicated personalised digital learning resources at your disposal. Many primary and secondary school children are not as savvy and used to navigate through the various tasks of information retrieval, fact check, upload and download projects, and so on, unlike, say, students who have tried a MOOC.

I reflect João's perspective of how learners experienced the switch to remote but will add thoughts on the teachers' perspectives which are just as valid. We read in the media what big tech companies can do for education and how education problems can be solved (Fullan and Quinn 2020; Department for Education 2020), but student and teacher voices seem to never count. For example, whatever the "new solutions' that keep coming to the classroom (in the more developed world but also in the fringes of the less developed world), teachers and students are also now forced to learn and master the features of these new platforms 'in record time' (Nuere and de Miguel 2020). It is also the responsibility of these same teachers to configure security and data privacy features and oversee the welfare and interactions of students on the learning platform to prevent inappropriate behaviour. These are nuanced yet important tensions that continue to challenge educational processes and dampen inequalities. A teacher needs to know how to avoid zoom-bombing or cyberbullying incidents now that most learning takes place online, and collaboration and communication are digitally mediated (discipline was more visible in the classroom than it is via chatrooms and on online shared documents).

Indeed, while the lack of teachers, resources, and access to basic necessities existed before the pandemic, some new realities emerged. The shortcomings of national frameworks for technology governance and digital development were now being propagated downward and across all levels of society by country development agendas that were also struggling to survive the scourge of the pandemic. For instance, the lack of robust and effective regulations for data governance and protection in some $30 \%$ of world jurisdictions (UNCTAD 2016) created a dilemma for users who now had to make sudden digital transitions to EdTech platforms that seemed to be driven more by the desire to make profit than to solve problems through the creation of utility (Teräs et al. 2020). With cybersecurity incidents 
surging up to $800 \%$ in the aftermath of the pandemic (MonsterCloud 2020), independent cybersecurity organisations, law enforcement, and national agencies for cybersecurity and digital incidence response (Cimpanu 2020) had to deal with exponentially more cases than before. As a result, the existing challenges and risks to security and safety in EdTech became amplified by these sudden transitions to distance learning (Newman 2020).

VH: The centralised-decentralised paradigm is interesting. It brings the question of the learning process itself and the need to review it in its foundation. The social environment motivates and fosters learning (Vygotsky 1978) as much as building self-efficacy (Bandura 1986), self-navigated (Papert 1993), and experiential learning (Dewey 1938, 1963). We cannot assume that teachers are solely responsible for student success just as we cannot submit to the narratives of EdTech solutionism. When learners take responsibilities for their own learning, organise and create learning systems, deploy creative ways to reiterate what was learned, find meaningful ways to practise, and experience what was learned, learning outcomes are substantially positive (Rubin and Tompson 1982).

This is to say that the pandemic did not simply break away from a centralised form of learning to a new - decentralised - untested form where everyone subsequently would suffer. Rather, it underlines an essential condition of learning, which we could focus on as a silver lining. For instance, Huberman argued that in bringing innovations to the learning process (new programs, products, technologies), we should not 'spend too much time on the spectacular at the expense of the fundamental' (Huberman 1983: 478). For one, it remains difficult to account for the spectacular without the fundamental. And two, if the fundamental is not there, how much can one hope for the spectacular to live up to its promises? One of the fundamentals, as João suggests, is the social interaction, what social-cultural theorists (Vygotsky 1978) acknowledge as crucial to the learning process. Another fundamental is to teach learners how to develop systems of learning regardless of the availability of the 'spectacular' or the lack of it.

ECO: The social connectedness is a missing piece in many of the new digital learning methodologies deployed during the pandemic. In traditional learning environments, students are able to hang out together outside the regular class schedule, either among themselves or in consultation with the teacher, to discuss difficult subject matters for which the regular class schedule was not enough to provide sufficient depth and understanding for the learner(s). However, in the methodologies adopted particularly in developing contexts following the onset of the pandemic, it became difficult to achieve this configuration due to high costs of Internet access (UNHCR 2020), attend online class, and any extra interactions outside class schedules became an additional expenditure that both teachers and learners couldn't afford in my region.

JPM: The centralised versus decentralised views I provided earlier underlie the challenges at the infrastructural level, and I totally agree that this change of paradigm arises new question marks and opportunities on the learning side. One I find interesting is how younger generations perceive the value of the education they receive. Note that I used the word receive because it is only after the value is acknowledged by youth that education becomes a shared responsibility process. 
Now that students are at home and found the freedom to work at their own pace, a complementary effort needs to be put forward to provide better tangible use cases of the pertinence of learning certain topics, not simply because they are mandatory or of personal interest but rather that they could further leverage youth future.

Digital literacy comes again as the topic of the now, and like Emmanuel was saying, relevant to both the expert - the teacher - and the learner. That leaves me to reason about the social aspect of learning. While you can evolve competences on your own by continuous practice, learning as part of a group helps speeding up the process due to social behaviours such as competition, cooperation, imitation, and questioning. Peer learning and sharing are essential to make better citizens as well, so under current circumstances of physical distancing, technology is put on the spot to bridge interaction among learners. The sooner we understand and accept this communication is inherently different from the one we could achieve in-person and by the centralised approach, the sooner we can adapt and embrace ways of ensuring it in this new education age.

VH: What are youths' perceptions about how their education is 'delivered' and 'platoformised'? Research is not optimistic about learning platforms with high MOOC dropout rates despite their convenience and accessibility (Kizilcec et al. 2020). What are your thoughts on the new mediated learning environments, enforced due to the pandemic, and where these were made possible?

JPM: An impressive number of digital platforms and applications swarmed different subjects and courses; to put it simply, education became messy. When you have to put so much effort to keep up with the different platforms, you lose focus and precious time that could have been put up to actually learn. A big plus in digital remote education is how asynchronous learning can be leveraged to reduce the resources that synchronous learning demands, something only tangibly possible in the previous educational model in the form of homework. Going remote, students are increasingly able to decide when and where they want to learn a certain topic and that is really interesting to promote autonomy and responsibility.

Here is a small example: on a synchronous focused set up, everyone has classes at the same time, and the timetable is set by someone else than the students, so how does that address the differences in productivity that are inherently human? Now consider an asynchronous-focused model: students that tend to be more active and productive in the morning can start early, and those who slept over the early classes simply because they could not focus can now optimise their time and watch them a bit later in the day. Moving to the asynchronous paradigm raised challenges, mainly on the social aspect of education (Alhumaid 2019).

It is easy to forget the group aspect of learning when you have the freedom to do your own timetable. I see that as a disadvantage because you tend to interact less with peers and teachers. The advantages of the now possible asynchronous-oriented education are trapped by the confluence of different platforms and by the failure in promoting education as a social process.

ECO: A recent research by Cahapay (2020) underscores how the realities of the pandemic have challenged the four elements of curriculum - goal, content, approach, and evaluation (italics intentional). We are challenged, in particular, by how assessment is done; we need to reconsider and redefine the metrics and 
performance indicators that are currently being used in some jurisdictions (Osadebe 2015) to measure teaching and learning outcomes, as these may not particularly reflect the true picture of the learners' abilities in the pandemic conditions.

Here is what I mean: in face-to-face learning environments, things like class attendance, completing assignments, and participating in group learning tasks have long been as part of continuous assessment metrics for measuring performance of learners and students (Hayford 2003). However, with the ubiquity the digital has brought as a form of learning, and the flexibility that asynchronous learning provides even in blended approaches, it may be important to rethink some of these continuous assessment metrics.

For example: how would you measure that a student has attended a class in a virtual learning classroom? Should the absence of a student from a scheduled class and time, automatically translate into a learner's failure? Do virtual classrooms remain available for students to come in and engage outside the scheduled class time? If yes, who or what regulates the interactions that take place outside scheduled class time? How flexible would a teacher be in managing deadlines on assignments and other assessment activities? These questions underscore the inadequacies of the current assessment metrics being adopted in some jurisdictions in the African region; they have to be rethought and student and teacher voice have to be included in the process.

\section{Radical Restructuring or Temporary Arrangements?}

VH: At work, unlike at an educational institution, management might consider more flexibility depending on employee traits (e.g. 'morning' person or an individual with young children) to improve company efficiency and effectiveness (Dowling 2019). Inclusivity and flexibility (Agarwal 2018) to ensure that everyone is productive could be a good model for educational institutions, too. The pandemic has challenged institutions worldwide to provide the basics (e.g. access to resources, connection, lesson, assessment and so on), but it may also be an opportunity to seek more flexible and inclusive teaching and learning models. New models will need to rethink assessment as Emmanuel points out. Then also, a new model for a class may not be a class of same-aged students; they may not even have to meet at the same time because some would prefer to study later, others earlier. If the classroom reflected the factory of the early nineteenth century, what should the classroom of the twenty-first century reflect? Let us reimagine school as youth see it. Can you draw your scenario of an ideal learning environment considering some of the preand post-Covid-19 advantages and challenges you experienced?

ECO: In many ways, I would consider an ideal school, post-Covid-19, to be one in which an array of digital learning platforms is available for learners to choose from. Wherein learners are also able to choose what class time(s) works best for them without any negative consequences, teachers also provide a range of digital office hours weekly that students can choose from.

Blended learning methodologies should be popularised in such an ideal school, and virtual classrooms should also be hosted in a way that they are available for use 
outside regular class hours. Students can come in to socialise and discuss issues. Assessment should be more result- and less deadline-driven. This would help to minimise or prevent the burnouts that have become a cause for much concern in the current deployments of EdTech. For the developing world, national educational frameworks should consider low-cost Internet access, accessibility to digital services, and infrastructure even for rural communities.

JPM: The word inclusion is key to design of an ideal school. We want to ensure that everyone has the chance to learn what is more relevant and useful to them, at their own pace and around others who share similar interests. Such student-centred vision should be leveraged by the technological developments that rapidly emerged given the pandemic outbreak by: providing wider access to information, that in turn can be augmented and distilled into meaningful knowledge by collaborative learning processes that are based on individual competences; allowing for the flexibility of learning in different spaces and times, which could be done through virtual hubs that can link onsite and remote students; and lastly, connecting the dots and help approximate students and teachers. Another point I would stress is the importance of ever engaging in hands-on learning, improving gamification strategies, and experimentation as the base of knowledge transfer.

VH: Ivan Illich envisioned the sort of 'learning webs' (1972) where anyone who wants to learn can connect with likeminded or experienced others in the field of their interest in a seamless way and learn whenever they can or want. Such ideal, if not radical, scenarios go against the dominant business models of education. If you look at the revenue of the education industry, free learning webs that challenge these business models will be hard to accept. The turnover of the UK education industry (universities alone) for 2019 was estimated at $£ 48.8$ billion (Varrella 2020). With the pandemic, where that turnover is highly dependent on international students is greatly challenged still. UK universities will have to reconsider their models and rethink their sustainable futures. In the USA, the education market revenue for 2020 is $\$ 77.1$ billion (Statista 2020). This is a potent industry, coupled with the EdTech market, which is estimated to reach $\$ 285$ billion by 2027 (PRNewswire 2020). Is your generation ready for learning webs, blended learning and flipped-model classrooms that can challenge the business of education?

JPM: I could consider things outside youth's scope that might make these models not work. The business model needs rethinking, perhaps moving towards an approach that captures capital directly from industry to the individual and ensure it benefits students directly. As students, we are already prone to be stimulated with information all the time. Envisioning a shift towards even more peer interconnection is a question of moving the same super interactive features we get in entertainment platforms towards the education playfield. To some extent, I also think these different issues are being brought to students in a more transparent way, so it is the case that this generation is more ready to take the leap.

ECO: Digitization, coupled with the gains that have been made by years of development efforts in trying to narrow the digital divide, has helped bring the benefits of digital learning closer to many youths who were previously unconnected from these gains. The result I see, and perhaps one profound evidence for the long-term future of learning webs, blended learning, and flipped model classrooms, is that youth are 
gradually taking charge of their own learning. They are beginning to pursue more of the knowledge, skills, and abilities (Darling-Hammond et al. 2019) that matter most to their interests and life goals, as a way of making up for the deficiencies of the current exams-focused approach to traditional curricula (Cairns 2020). Perhaps, this might also explain the growing popularity of EdTech platforms like Coursera, Udemy, and Khan Academy.

VH: Share experiences and conversations you have had with friends and colleagues from the first days of lockdown. Did any tensions or challenges emerge?

JPM: Initially everyone was talking about how going remote was just trying to digitalise every process to make it available at distance. Coming from a computer engineering background, my teachers did not face the same challenges as others did, who were completely unprepared to use certain digital platforms (Schleicher 2020). Another aspect is how hard it is to create the necessary boundaries between the mindset of fun and entertainment you are most used to at home and the learning moments. The synchronous classes did not allow for casual debates to emerge like they used to and that was even less possible in pre-recorded classes.

ECO: The discussions within my circle centred around preparedness and the accompanying fears about how the sudden rapid transitions were likely to lead to haphazard outcomes that could threaten the very foundations of traditional (faceto-face) learning that was the norm in my developing country situation. In a country where the minimum monthly wage sits comfortably below \$100 USD (Varrella 2020), the key concern for many at the beginning of the lockdown was how to cope with the rising cost of consumer goods and services across the country and the cost of maintaining Internet access which had now more than tripled with the sudden (almost total) digital transitions in trying to adhere to the imperatives of physical distancing in order to avoid getting infected and sick.

For many within my circle, the real tension was the struggle between being able to afford at least a meal a day, being able to meet up with the cost of Internet access subscription to complete a school semester that had suddenly transitioned online due to the pandemic, and being able to meet other civil responsibilities (paying utility bills, medicals, etc.). These were in addition to contending with several existing systemic challenges to education for career development, some of which have already been reported by existing research (Chebib 2020).

The social strain quickly began to weigh in for many, as the realities of the digital divide in the context of a developing country meant that young students who were schooling and trying to pursue careers in urban areas were constrained to make a difficult choice between remaining in the urban towns and cities where digital infrastructure was more available and reliable to meet the needs of their educational and career pursuits and returning to their families in the villages where social amenities and digital infrastructure were virtually non-existent.

VH: The lines between school and home are blurring, the way they have been in relation to work and home. A community platform that helps people outsource tasks and find local services recently found out that while remote workers tend to become around $10 \%$ more productive, when the boundaries between work and home become hazier, $29 \%$ of these workers also tend to perform much worse and 54\% reported that their health has suffered (Airtasker 2020). Your initial experience from the first 
wave of lockdown was the hardship you and peers experienced to create the necessary boundaries between the relative comfort of being home and the need to focus on your studies. Surely different youth experienced these challenges differently.

ECO: Indeed, that is why researchers, educators, and the public addressing issues relating to youth and EdTech should consider the wider spectrum. Then, personal challenges were only exacerbated and amplified by the pandemic and the resulting lockdowns. Beyond this, however, they also seem to highlight the challenges of digital citizenship and digital participation in developing countries, not only in relation to education but also career development. The real concern from my side of the world was the difficult choice many youths had between learning and career development and going for social support - to the family back in the village or cutoff rural area.

JPM: Assuming we can identify ourselves with either the group that improved performance or the one that lost it once the lockdown was implemented and education became remote, I can infer it is a wider problem that, although personally experienced, should be tackled with better emotional education (Christensen 2020). Unfortunately, this exercise was left out for students to solve because the teachers were also unused to such challenges. It is true that there was remote work and activities already before the pandemic, but these were optional. The pandemic forced students to take the remote school-from-home. On top of this, such hard change was unprecedented, causing more noise and stress until we all adapted, stress that still lingers.

VH: Nuances exist in how well one adapts to the new mode of asynchronous learning, for that matter, how well or not one adapts to remote work. How much is that technically determined beyond the necessary skills and competencies to navigate through the university or work software and resources? To teach or learn in a meaningful way demands a systematic process, critical thought, good organisation, and so on - skills are not determined by EdTech. If, on the one hand, the issue is about lack of connectivity and digital resources in local languages, in those societies where this problem is less acute, EdTech has not served well either. In pre-pandemic times, we have seen the persisting problems of underused technologies (Davis 2019; Paton 2020). If access could be the problem, where it is less so, how it improves learning and teaching remains debatable.

JPM: That is perhaps a topic that only time will be able to shed a light on. I mean, I am part of the first generation that experienced digital technology like the home computer and the Internet at elementary school - and generations younger than me today have started to do so even earlier - but we are only now achieving the maturity phase of entering the work market. It will take time to fully assess the impact of technology in education and its impact in the development of competences. Now the question might be about the preparedness of youth to join the work market, but in the future, it might be how to learn simply not to work, given the improvements in automation and artificial intelligence.

ECO: Organisation and self-control are critical attributes necessary for harnessing technologies to our benefit. I have thought over this a lot since the first lockdown, and the sudden transitions to digital learning. Should remote learning and EdTech solutions be deployed for all categories of learners, regardless of 
age and maturity? If not, then what solutions are best suited for what demographics of learners? How can we measure learning outcomes in these new conditions? Demographics, organisational skills, self-efficacy - all these are skills that precede the EdTech debate. These are the skills young people need to work. Looking at the argument this way, Internet access and digital technologies should be seen more as a utility rather than as our perceived need.

VH: Throughout the lockdown, you have been studying from home. School's compartmentalisation of timed lessons is gone. There is also social media and family members around. Have you and peers been able to cope and how?

JM: Infoglut and instant gratification is a cultural problem, and these might be decreasing the development of patience and other relevant self-control habits and even jeopardise the ability to make long future plans. The digital calls for instant rewards, micro-tasking, and over-optimising everything. We are living from one device to another, from one little task to another, losing the bigger picture (Drury 2020). Technology pushes the pace at which we live and consume things, which paradoxically compromises learning because learning is a process not a task and it takes time. We need time to reflect on the literature. We need time and space away from instant distractions to be creative. On the other side of the table are teachers that are on never ending catch-up with technology and new ways to motivate and force their knowledge into students. Again, the word force is not chosen randomly. Teachers now have to share their share of attention with other distractions in the entertainment range like influencers that bring much more appeal to the students or young people in general.

EO: I think that technology has played a huge role in amplifying cultural problems that have continued to pose challenges to learning: like instant gratification and over accessibility. Gradually, we are coming face-to-face with a new way of learning that sees learners prefer to familiarise themselves with the online locations where they can readily find answers to their questions (such as search engines, blogs, YouTube), as a more convenient alternative to exerting the patience and rigour that is needed to study and read books.

I do not think that teachers are insulated from these cultural challenges either, albeit from a subtly different dimension. With some digital learning and EdTech solutions (such as Google Classroom, Edmodo) offering integrated options for automatically grading and assessing quizzes, tests, and assignments, I consider that teachers also faced the temptation of enabling automatic grading functions on assigned assessments, as against having to manually read through dozens or scores of objective and essay answers submitted by students - which, indeed, could provide a better understanding of the learners' capabilities and also give the teacher valuable insights regarding how teaching methods could be better structured to accommodate the needs of different learners. Indeed, more open dialogues about these cultural propensities between stakeholders (teachers, learners, administrators, and regulators alike) at the intersection of education and technology might be necessary in order to begin to chart a progressive path forward. 


\section{The Sense of Urgency Is Misleading}

VH: The sense of urgency to fix education with EdTech's 'silver bullet' offerings concern me a lot. Learning is a slow process - whether one is learning how to write, speak a language, or play a music instrument. During the first wave of Covid-19, there was a sense of urgency regarding children's learning once schools shut their doors. Without denying the genuine effort for help, generally, and the benefits of networked technologies for connection, collaboration, and so on, the undercurrent of hasty proposals such as the UNESCO Coalition with some of the most powerful tech companies including Google, Facebook, and AWS, Microsoft's Deep Learning (Fullan and Quinn 2020) and Pearson's vision for a Netflix for education are not simply proposals for modernisation, progress, or solving school's problems. As such education can be seen as an attractive sector for platform capitalism.

I want to talk about what currently is in place in school where you are. We cannot deny that not everything is wrong with school. School, generally and historically speaking (hence the capitalization), has produced great many educated people - scientists, musicians, philosophers, and also great many pedagogues who have sought to understand the learning process. School, with all its flaws, has also brought about people who now critically examine the hasty technological transformation of education. School, with or without digital applications and platforms, also brings about young people like you - who want to contribute to society but who also want to have the freedom to shape your own future. Can we talk a bit about what is good about school from your perspectives - one representative of youth from Africa and one from Europe?

JM: I have to agree that things moved too fast, not technologically speaking because some of the tools were already out there and just got a new application, but rather human-in-the-loop speaking, meaning, technology was suddenly the lifeline to teach and learn in times of pandemic, and yet it came without instructions for that purpose. From a positive perspective, school represents one of the pillars of society because it unifies core values and basic understanding of the world and prepares youth for the future ahead by providing us with the bare knowledge to thrive on. EdTech should always be seen as a tool or a means to the end of transferring knowledge from one another. I am sure of the need to encapsulate a broad set of technologies under the term 'EdTech', because that would be a manageable mechanism to properly identify technical requirements, assess their pertinence, and evaluate their impact in the education process.

ECO: In my background and experience, I have come to understand how schooling and education might be different. Schooling relates more to the processes and procedures that are applied in the pursuit of knowledge through formal or semi-formal channels. Education has to do with being transformed or influenced by this knowledge in a positive way - either as it is being acquired or after it has been acquired, wherein this transformation or influence could manifest through social and civic relations, intellectual depth, and emotional resilience. We have seen how technology has helped to 'provide' a means for schooling to 
continue in the aftermath of the pandemic and the resulting lockdowns, which is a positive outcome - the social - not the physical—connectedness can continue, so there is no totality of isolation. But then, whether and how it has actually contributed to the broader and longer-term goals of education for career and life remains a subject for ongoing research and debate.

VH: Some argue that Covid-19 is used as pretext for big tech to spread tentacles in education (Hess 2020). Take the example with proctoring software. Producers claim that it accurately monitors and prevents students from cheating during exams taken at home. Cheating existed before Covid-19. The difference is that in prepandemic, teachers handled cheaters and cheating. Now the private sector does. Deploying surveillance software that generates student data with no student control over how it can be used, why and by whom (Van Dijck 2014), is a cause that goes beyond the educational. Who decides whether proctoring software will be used - teachers, schools, district administration? Do students have a say in that? What if one wants to opt out?

ECO: I think that these are crucially relevant questions, and to relegate or downplay their relevance could portend grave implications in the long run. Let me add more complexity to the scope by asking: What happens to the data that proctoring software collects about learners after the learning process or educational relationship is over? No one wants to be denied a job role several decades later because they were caught cheating on a test or detected to have plagiarised on a class essay many years ago and have been duly penalised for it. I think that what we need in these times is not more surveillance but rather more open dialogue, more engagement, more autonomous models for learners' accountability (that might be possibly incentivised). Because while it may seem foolhardy to ordinarily expect students not to cheat on a test or plagiarise on a class essay, it is possible to inspire and gradually nurture the measure of trust that would help learners to develop and adopt autonomous models for accountability in these matters.

JPM: The world is changing rapidly; school curricula tend to get behind. We need more digital literacy education from an early age and to initiate the discussion of the implications of a digital society. We are still lacking in soft skills: being exposed at an early age to the digital needs to be counterbalanced by strong social and self-awareness and failing to do so will result in ever worse generations. Proctoring is just another example of how wrong we are failing on the education process: it incentivises a paradigm of control and surveillance over one of trust.

\section{A Word About Work}

VH: The rise of youth unemployment has reached new heights. These figures are exacerbated by the Covid-19 pandemic (European Parliament 2020). If a young person could work in the interim of their studies in, say, the hospitality industry, this is no longer possible since everything is closed, and tourism is virtually non-existent. On the other hand, today the gig economy provides opportunities for project-based, temporary, and part-time work, but there are so many inequalities and risks of 
exploitation and unfair conditions there (Temperton 2018). How do you cope? What are the options for you?

JPM: I finished my Masters' degree during the pandemic. This suddenly put things in perspective as the power of negotiation and promoting my just-acquiredskills was suddenly swept away by business safeguards that stopped junior admissions. There is always the choice of proceeding with my studies and specialising further, but this is not for everyone and might come at the expense of focusing on something that might prove unhelpful in the current circumstances that call for diversified skill sets acquired directly while working in the industry.

Covid-19 just speeds up things, but we are moving to a place where employment might significantly decrease, because of automation and intelligent systems, and the new challenge around the corner will be education towards fulfilment without a job. As an AI researcher, I am fully aware of all of these and have come to terms with it, but I am sure it will be hard, perhaps we get the time to do it right, like we did not to adapt this new digital education imposed by Covid-19.

ECO: I am excited about the future of work in these times. One lesson that I have learned from working in the times of the Covid-19 pandemic is that work has shifted to more ubiquitous, borderless, and value-based dispensation. But then again, the risks in these dispensations are equally critical. The options for me have been to keep deepening my capacity to bring value and contributions that are both unique and relevant to multi-disciplinary projects beyond the realms of my core competence and background, while also trying to understand what dangers might lie ahead in domains that I am not familiar with but interested to work in.

\section{Conclusion}

VH: Youth voices bring a crucial and highly needed side within a fast-changing education ecosystem, one in which, propelled by the pandemic, corporate influences continue to grow and have a greater say in how its processes can - or should - be transformed. EdTech as João and Emmanuel discuss are needed as tools that enable and facilitate existing processes, tools that allow connection, creativity, collaboration, and access to various resources. However, to work well, some educational processes need restructuring that may call for reorganising a classroom to finding meaningful ways to continue the human socialisation that is otherwise lost when hanging on campus is not available. Importantly, the more fundamental factors that facilitate learning also remain a priority. Emmanuel highlighted in his words the reality of his community in Ghana that when the pandemic hit, the priorities were to afford at least a meal a day, and then to be able to meet up with the cost of Internet access subscription to complete a school semester. From the most basic necessities to the ability to self-organise, resist distractions when physical spaces - the home and school - are blending and creating a system for it all were the most important elements for young people to carry on with their education and building a future.

On the flip side, the surveillance that technologies can enable through data collection and the pitfalls of platforms (such as those providing MOOCs) are discouraging to young people. The undercurrents of platform capitalism through the means of 
personal data extraction can further pose risk to young people's voices and choices. Today, we see powerful providers of educational products such as Pearson education reimagine education as a form of on-demand platformisation whose algorithms can have the capacity to override human decisions for curriculum and pedagogy and steer decisions with regard to college and career pathways for students (Waterson 2019). Other business entities are already proliferating in this area without much policy or societal resistance (Straumsheim 2015). These corporate influences in education have larger implications for the freedoms and choices young people can be left with, not only for their education but also for their future work.

In many ways, the pandemic forced the majority of societies to resort to basics - find the means in any ways they can to go on with their responsibilities, secure their livelihoods, and as much as possible, continue to pursue their dreams and goals. The few who could afford to 'reimagine' education - a pillar to democratic societies - have started to do so from the vantage point of their businesses (Waterson 2019; Fullan et al. 2020; Williamson 2021). The growing data extraction due to the ubiquitous digitisation of education enables a continuum of knowledge asymmetries. In return, these asymmetries empower EdTech businesses to drive their visions and designs for education and the future of work. This is precisely why, young people's voices must be ever louder, in defence of their rights and the freedom to choose and shape their own futures.

\section{References}

Agarwal, P. (2018). How do we design workplaces for inclusivity and diversity? Forbes, 19 July. https:// www.forbes.com/sites/pragyaagarwaleurope/2018/07/19/how-inclusive-is-your-organisation-hereis-how-to-use-inclusive-design/?sh=2482e6fa4d18. Accessed 5 March 2021.

Airtasker (2020). The benefits of working from home: comparing the productivity, spending and health of remote vs. in-office employees. https://www.airtasker.com/blog/the-benefits-of-working-fromhome/ . Accessed 5 March 2021.

Alhumaid, K. (2019). Four ways technology has negatively changed education. Journal of Educational and Social Research, 9(4), 10-20.

Amato, N. (2015). A lack of resources for many classrooms. The New York Times, 26 March. https:// www.nytimes.com/roomfordebate/2015/03/26/is-improving-schools-all-about-money/a-lack-ofresources-for-many-classrooms. Accessed 5 March 2021.

Andersen, C. U., Cox, G., \& Papadopoulos, G. (2014). Postdigital research - editorial. A Peer-Reviewed Journal About, 3(1).

Andrejevic, M., \& Selwyn, N. (2019). Facial recognition technology in schools: Critical questions and concerns. Learning, Media and Technology, 45(20), 115-128. https://doi.org/10.1080/17439884. 2020.1686014.

Bandura, A. (1986). Social foundations of thought and action: a social cognitive theory. Englewood Cliffs: Prentice Hall.

Blackall, M. (2021). 'Another year wasted': A-level and GCSE students react to cancelled exams. The Guardian, 7 January. https://www.theguardian.com/education/2021/jan/07/a-level-and-gcse-studentsreact-to-cancelled-exams. Accessed 5 March 2021.

Cahapay, B. M. (2020). Rethinking education in the new normal post-Covid-19 era: a curriculum studies perspective. Aquademia, 4(2), 1-5. https://doi.org/10.29333/aquademia/8315.

Cairns, R. (2020). Exams tested by Covid-19: an opportunity to rethink standardised senior secondary examinations. Prospects. https://doi.org/10.1007/s11125-020-09515-9.

Ceres, P. (2020). A 'Covid slide' could widen the digital divide for students. Wired, 8 July. https://www. wired.com/story/schools-digital-divide-remote-learning/. Accessed 5 March 2021. 
Chebib, K. (2020). Education for all in the time of Covid-19: how edtech can be part of the solution. London: GSMA Association. https://www.gsma.com/mobilefordevelopment/wp-content/uploads/2020/ 09/EdTech-Final-WEB.pdf. Accessed 5 March 2021.

Christensen, J. U. (2020). The importance of soft skills in a post-pandemic world. Forbes, 9 November. https://www.forbes.com/sites/ulrikjuulchristensen/2020/11/09/the-importance-of-soft-skills-in-apost-pandemic-world/?sh=52d458835c26. Accessed 5 March 2021.

Cimpanu, C. (2020). FBI says cybercrime reports quadrupled during Covid-19 pandemic. ZDNet, 18 April. https://www.zdnet.com/article/fbi-says-cybercrime-reports-quadrupled-during-covid-19-pandemic/. Accessed 5 March 2021.

Coughlan, S. (2021). Thousands of primary pupils face closed schools. BBC News, 4 January. https:// www.bbc.co.uk/news/education-55525681. Accessed 5 March 2021.

Darling-Hammond, L., Flook, L., Cook-Harvey, C., Barron, B., \& Osher, D. (2019). Implications for educational practice of the science of learning and development. Applied Developmental Science, 24(2), 97-140. https://doi.org/10.1080/10888691.2018.1537791.

Davis, R. M. (2019). K-12 districts wasting millions by not using purchased software, new analysis finds. EdWeek Market Brief, 14 May. https://marketbrief.edweek.org/marketplace-k-12/unusededucational-software-major-source-wasted-k-12-spending-new-analysis-finds/. Accessed 5 March 2021.

Department for Education. (2020). Schools to benefit from education partnership with tech giants. Thousands of schools to receive technical support to start using Google and Microsoft's education platforms. London: Department for Education. https://www.gov.uk/government/news/schools-to-benefitfrom-education-partnership-with-tech-giants. Accessed 5 March 2021.

Dewey, J. (1938). Experience and education. New York: Collier Books.

Dowling, D. (2019). Your company needs a better retention plan for working parents. Harvard Business Review, 1 February. https://hbr.org/2019/02/your-company-needs-a-better-retention-plan-for-workingparents. Accessed 5 March 2021.

Drury, I. (2020). The problem with instant gratification and how it affects our society: can we really blame Amazon? Dialogue \& Discourse, 9 September. https://medium.com/@isabelle.s.drury. Accessed 5 March 2021.

European Parliament. (2020). COVID-19: How the EU fights youth unemployment. Brussels: European Parliament. https://www.europarl.europa.eu/news/en/headlines/society/20200709STO83004/covid-19how-the-eu-fights-youth-unemployment. Accessed 5 March 2021.

Fleming, N. (2021). After Covid, will digital learning be the new normal? The Guardian, 23 January. https://www.theguardian.com/education/2021/jan/23/after-covid-will-digital-learning-be-the-newnormal. Accessed 5 March 2021.

Fullan, M., Quinn, J., Drummy, M., \& Gardner, M. (2020). Education re-imagined: the future of learning. A collaborative position paper between New Pedagogies for Deep Learning and Microsoft Education. Microsoft Education. http://aka.ms/HybridLearningPaper. Accessed 5 March 2021.

Grubic, N., Badovinac, S., \& Jorhi, M. A. (2020). Student mental health in the midst of the COVID-19 pandemic: A call for further research and immediate solutions. International Journal of Social Psychiatry, 66(5), 517-518. https://doi.org/10.1177/0020764020925108.

Hayford, L. (2003). Reaching Underserved Populations with Basic Education in Deprived Areas of Ghana: Emerging Good Practices. Ghana: CARE International.

Henley, J. (2021). As parts of UK enter third Covid lockdown, how does rest of Europe compare? The Guardian, 5 January. https://www.theguardian.com/world/2021/jan/05/as-parts-of-uk-enter-third-covid-lockdownhow-does-rest-of-europe-compare. Accessed 5 March 2021.

Hess, F. (2020). No, COVID-19 is not a swell chance to market your Ed-Tech 'solution'. Forbes, 13 March. https:/www.forbes.com/sites/frederickhess/2020/03/13/no-covid-19-is-not-a-swell-chance-to-marketyour-ed-tech-solution/. Accessed 15 March 2021.

Hillman, T., Rensfeldt, B. A., \& Ivarsson, J. (2020). Brave new platforms: a possible platform future for highly decentralised schooling. Learning, Media and Technology, 45(1), 7-16. https://doi.org/10. 1080/17439884.2020.1683748.

Huberman, M. (1983). Recipes for busy kitchens: a situational analysis of routine knowledge use in schools. Knowledge: Creation, Diffusion, Utilization, 4(4), 478-510. https://doi.org/10.1177/ 0164025983004004002 .

Illich, I. (1972). Deschooling society. New York, NY: Harper \& Row.

Jandrić, P., Knox, J., Besley, T., Ryberg, T., Suoranta, J., \& Hayes, S. (2018). Postdigital Science and Education. Educational Philosophy and Theory, 50(10), 893-899. https://doi.org/10.1080/00131857. 2018.1454000 . 
Kewalramani, S., Arnott, L., \& Dardanou, M. (2020). Technology-integrated pedagogical practices: a look into evidence-based teaching and coherent learning for young children. European Early Childhood Education Research Journal, 28(2), 163-166. https://doi.org/10.1080/1350293X.2020.1735739.

Kizilcec, F. R., Reich, J., Yeomans, M., Dann, C., Brunskill, E., Lopez, G., Turkay, S., Williams, J. J., \& Tingley, D. (2020). Scaling up behavioural science interventions in online education. Proceedings of the National Academy of Sciences, 117(26), 14900-14905. https://doi.org/10.1073/pnas.1921417117.

Li, C., \& Lalani, F. (2020). The Covid-19 pandemic has changed education forever. This is how. World Economic Forum, 29 April. https:/www.weforum.org/agenda/2020/04/coronavirus-educationglobal-covid19-online-digital-learning/. Accessed 20 April 2021.

Maris, E. (2019). Why young climate activists have captured the world's attention. Nature, 573, 471472. https://doi.org/10.1038/d41586-019-02696-0.

Mondragon, I. N., Sancho, B. N., Santamaria, D. M., \& E. A. Munitis (2021). Struggling to breathe: a qualitative study of children's wellbeing during lockdown in Spain. Psychology \& Health, 36(2), 179-194. https://doi.org/10.1080/08870446.2020.1804570.

MonsterCloud (2020). Top cyber security experts report: 4,000 cyber attacks a day since Covid-19 pandemic. PRNewswire, 11 August. https://www.prnewswire.com/news-releases/top-cyber-securityexperts-report-4-000-cyber-attacks-a-day-since-covid-19-pandemic-301110157.html. Accessed 20 April 2021.

Newman, H. L. (2020). Schools already struggled with cybersecurity. Then came Covid-19. Wired, 7 January. https://www.wired.com/story/schools-already-struggled-cybersecurity-then-came-covid-19/. Accessed 5 March 2021.

Nuere, S., \& de Muguel, L. (2020). The digital/technological connection with Covid-19: an unprecedented challenge in university teaching. Technology, Knowledge and Learning. https://doi.org/10. 1007/s10758-020-09454-6.

Osadebe, U. P. (2015). Evaluation of continuous assessment practice by university lecturers. International Journal of Evaluation and Research in Education, 4(4), 214-229.

Papert, S. (1993). Mindstorms: children, computers, and powerful ideas. New York, NY: Basic books.

Parker, K., Horowitz, M. J., \& Brown, A. (2020). About half of lower-income Americans report household loss due to Covid-19. PEW Research Centre, 21 April. https://www.pewsocialtrends.org/2020/ 04/21/about-half-of-lower-income-americans-report-household-job-or-wage-loss-due-to-covid-19/. Accessed 5 March 2021.

Paton, G. (2020). Schools wasting ‘ $£ 450$ million a year’ on useless gadgets. The Telegraph, 16 November. https://www.telegraph.co.uk/education/educationnews/9681317/Schools-wasting-450m-a-yearon-useless-gadgets.html. Accessed 5 March 2021.

Persson, J. (2020). The state of data 2020 report: mapping children's data in state education in England. Defend Digital Me, October. https://defenddigitalme.org/2020/10/the-state-of-data-2020-reportlaunch/. Accessed 5 March 2021.

PRNewswire. (2020). Top cyber security experts report 4,000 cyberattacks a day since Covid-19 pandemic. PRNewswire, 11 August. https://www.prnewswire.com/news-releases/top-cyber-security-exper ts-report-4-000-cyber-attacks-a-day-since-covid-19-pandemic-301110157.html. Accessed 5 March 2021.

Reidy, T. (2020). 'Recruitment is on hold': the students graduating into the Covid-19 recession. The Guardian, 10 April. https://www.theguardian.com/education/2020/apr/10/recruitment-is-on-holdthe-students-graduating-into-the-covid-19-recession. Accessed 5 March 2021.

Rubin, J., \& Thompson, I. (1982). How to become a more successful language learner. Boston, MA: Heinle \& Heinle.

Schleicher, A. (2020). The impact of Covid-19 on education: insights form education at a glance 2020. Paris: OECD. https://www.oecd.org/education/the-impact-of-covid-19-on-education-insights-education-at-aglance-2020.pdf. Accessed 5 March 2021.

Sellgren, K. (2019). Teachers 'paying for resources out of own money'. BBC News, 18 April. https:// www.bbc.co.uk/news/education-47964154. Accessed 5 March 2021.

Selwyn, N. (2014). Digital technology and the contemporary university. London and New York: Routledge.

Stiglitz, J. (2020). Conquering the great divide. International Monetary Fund. https://www.imf.org/external/ pubs/ft/fandd/2020/09/COVID19-and-global-inequality-joseph-stiglitz.htm. Accessed 5 March 2021.

Straumsheim, C. (2015). Completing the 'student life cycle'. Inside Higher Ed, 23 February. https://www. insidehighered.com/news/2015/02/23/student-success-company-hobsons-acquires-starfish-retentionsolutions. Accessed 5 March 2021. 
Strauss, V. (2020). As schooling rapidly moves online across the country, concerns rise about student data privacy. The Washington Post, 20 March. https://www.washingtonpost.com/education/2020/ 03/20/schooling-rapidly-moves-online-across-country-concerns-rise-about-student-data-privacy/. Accessed 5 March 2021.

Temperton, J. (2018). The gig economy is being fuelled by exploitation, not innovation. Wired, 8 February. https://www.wired.co.uk/article/gig-economy-dpd-courier-taylor-review. Accessed 20 April 2021.

Teräs, M., Suoranta, J., Teräs, H., \& Curcher, M. (2020). Post-Covid-19 education and education technology 'solutionism': a seller's market. Postdigital Science and Education, 2(3), 863-878. https://doi. org/10.1007/s42438-020-00164-x.

UNCTAD. (2016). Data protection regulations and international data flows: implications for trade and development. New York and Geneva: United Nations. https://www.tralac.org/images/docs/9500/ data-protection-regulations-and-international-data-flows-implications-for-trade-and-developmentunctad-april-2016.pdf. Accessed 5 March 2021.

UNESCO. (2020). Pupil-teacher ratio, primary. Paris: UNESCO Institute of Statistics.

UNHCR. (2020). Considerations \& options for connected education: Covid-19 response. https://www. unhcr.org/en-us/publications/education/5e $81 \mathrm{cf} 1 \mathrm{~d} 7 /$ considerations-options-connected-educationcovid-19-response.html. Accessed 5 March 2021.

Van Dijck, J. (2014). Datafication, dataism and dataveillance: Big data between scientific paradigm and ideology. Surveillance \& Society, 12(2), 197- 208. https://doi.org/10.24908/ss.v12i2.4776.

Varrella, S. (2020). Monthly minimum wage in Nigeria 2018-2020. Statista. https://www.statista.com/ statistics/1119133/monthly-minimum-wage-in-nigeria/. Accessed 5 March 2021.

Vygotsky, L. (1978). Mind in society: the development of higher psychological processes. Cambridge, MA: Harvard University Press.

Waterson, J. (2019). Pearson shifts to Netflix-style subscription model for textbooks. The Guardian, 16 July. https://www.theguardian.com/media/2019/jul/16/pearson-netflix-style-rental-academic-textbooks. Accessed 5 March 2021.

Williamson, B. (2017). Big data in education: The digital future of learning, policy and practice. London, UK: Sage.

Williamson, B. (2021). Making markets through digital platforms: Pearson, edu-business, and the (e) valuation of higher education. Critical Studies in Education, 62(1), 50-66. https://doi.org/10.1080/ 17508487.2020 .1737556$.

Yu, J., \& Couldry, N. (2020). Education as a domain of natural data extraction: analysing corporate discourse about educational tracking. Information, Communication \& Society. https://doi.org/10.1080/ 1369118X.2020.1764604.

Zhang, D., \& Livingstone, S. (2019). Inequalities in how parents support their children's development with digital technologies: Parenting for a Digital Future: Survey Report 4. London: LSE. https:// www.lse.ac.uk/media-and-communications/assets/documents/research/preparing-for-a-digitalfuture/P4DF-Report-4.pdf. Accessed 5 March 2021. 